https://doi.org/10.31713/m1024

\title{
COMPARISON OF THE STRUCTURAL PROPERTIES OF CONCRETE BEAMS WITH COMPOSITE BASALT AND STEEL REINFORCEMENT
}

\author{
Sakhno S.
}

Kryvyi Rih National University, Ph. D., Assoc. Prof., Ukraine

Yanova L.

Kryvyi Rih National University, Ph. D., Assoc. Prof, Ukraine

Pischikova O.

Kryvyi Rih National University, Ph. D., Assoc. Prof, Ukraine

\begin{abstract}
The subject of the study. The work investigated the deformative, strength, and cost parameters of concrete beams with various reinforcement types. The nature of the behavior under a load of beams reinforced with steel reinforcement and beams with basalt reinforcement of multiple diameters has been studied.

A research methodology is the studying of finite element models of the reinforced concrete beam. The Drucker-Prager model was used to simulate concrete behavior. For steel reinforcement, a bilinear isotropic hardening model, a linear orthotropic model was used for composite reinforcement.

The goal is to reveal the advantages and disadvantages of using basalt composite reinforcement in reinforced concrete.

Conclusion of the study.

The paper considers the behavior of four models of reinforced beams. In the first model, a control one, steel reinforcement, is used. In the second, the composite reinforcement diameter is equal to the diameter of the steel one. In the third model, the diameters of the composite reinforcement are taken from the conditions of its similar bearing capacity with the steel one. The fourth model's composite reinforcement diameters have been taken from the requirements of its equal deformation with the steel one. The paper presents a method for calculating the corresponding diameters of reinforcement. The model in which the diameters of the composite reinforcement are taken from the conditions of its equal deformation with the steel reinforcement has the beam's best operation. In this case, the deformations and stresses in concrete practically do not differ from the corresponding stresses in the model with steel reinforcement. However, the utilization factor of the bearing capacity of the reinforcement in this model is deficient, and the cost of reinforcing elements is almost three times the cost of steel rods. The model in which the diameters of composite reinforcement are taken based on its equal bearing capacity with steel reduces the cost of reinforcement almost three times. However, such a beam's deformation and strength properties are significantly worse than in the control sample. The model with composite reinforcement diameters equal to the
\end{abstract}


steel reinforcement diameters has no advantages over the model with steel reinforcement.

\section{Introduction}

Composite materials are increasingly used in mining, automotive, aerospace, construction, and other industries. Compared with metal, composite materials have a lower specific gravity, high specific strength, high corrosion resistance $[1,2]$. In construction, composite materials are used in the restoration and repair [1] of such structural elements as beams [3] and walls [4].

Composite materials are used relatively recently as bar reinforcement. The most widely used are fiberglass, this is due to its low cost and availability in the market $[5,6]$. Still, carbon fibers have excellent prospects [7]. They are much tougher than glass fibers and have a modulus of elasticity, like steel [5].

Since the beginning of the century, basalt fiber has been increasingly used [6-10]. The primary basalt deposits are in Ukraine [6]. Compared to steel, basalt composite rebar has a higher tensile strength - 1000-1300 MPa, but a much lower Young's modulus about $70 \mathrm{GPa}$.

Currently, there are many disputes about the effectiveness of basalt rebar. Supporters of this building material note the high bearing capacity, corrosion resistance, and cheapness of the material [2]. Opponents point to a low modulus of elasticity of the material and, accordingly, a more significant deformation under load and more extensive cracking in reinforced concrete [12,13,18].

This work aims to identify the advantages and disadvantages of using basalt rebar in reinforced concrete by analyzing the behavior of digital models of reinforced concrete beams. The deformation and strength characteristics of the models and some cost indicators were used as analysis parameters.

The modeling of these structural elements' operations with different reinforcement options was carried out to compare the behavior of concrete beams reinforced with steel and basalt reinforcement. The simulation was carried out by the finite element method in the ANSYS Student software package.

\section{The geometrical parameters}

The geometric parameters of the numerical model of the reinforced beam shown in Fig. 1. A concrete beam measuring 
$2080 \times 220 \times 120 \mathrm{~mm}$ mounted on two supports with a span of 1800 $\mathrm{mm}$. Both supports have a rotational degree of freedom around the $Z$ axis. One of the supports rigidly fixed along the $X, Y, Z$ axes; the other moves freely along the $X$-axis. The concentrated loads on the beam's upper chord transmitted through prismatic pads installed at a distance of $600 \mathrm{~mm}$ from the supports axes.

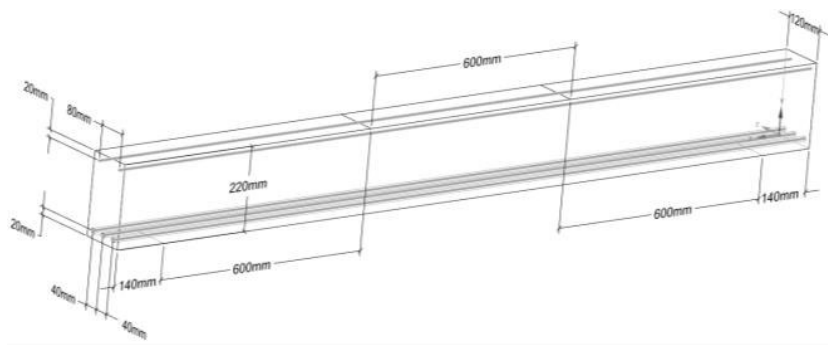

Fig. 1 The geometrical parameters of the numerical model of a reinforced concrete beam

There are some rebars in the upper and lower chord of the beam. In the lower zone - three rods with an interval of $40 \mathrm{~mm}$ along the axes, in the upper location - two rods with a gap of $80 \mathrm{~mm}$ along the axes. The distance from the rods' axes to the beams' surface is assumed to be $20 \mathrm{~mm}$.

\section{Material properties}

The work investigated the nonlinear behavior of materials. The Drucker-Prager model was used to model the concrete behavior. The concrete parameters for the Drucker-Prager model investigated in the works. [15-16]. The concrete mechanical and physical properties used in the numerical model shown in Table 1.

Table 1

Physical and mechanical properties of concrete

\begin{tabular}{l|c|c}
\hline \multicolumn{1}{c|}{ Density } & $2,3 \mathrm{e}-06$ & $\mathrm{~kg} / \mathrm{mm}^{3}$ \\
\hline Isotropic Elasticity Derive from & Young's Modulus and Poisson's Ratio \\
\hline Young's Modulus & 32500 & $\mathrm{MPa}$ \\
\hline Poisson's Ratio & 0,2000 & \\
\hline Bulk Modulus & 18056 & $\mathrm{MPa}$ \\
\hline \multicolumn{2}{|c}{ Drucker-Prager Base } \\
\hline \multicolumn{2}{|c|}{13542} & $\mathrm{MPa}$ \\
\hline Uniaxial Compressive Strength & 38,350 & $\mathrm{MPa}$ \\
\hline Uniaxial Tensile Strength & 3,4100 & $\mathrm{MPa}$ \\
\hline Biaxial Compressive Strength & 59,780 & $\mathrm{MPa}$ \\
\hline
\end{tabular}


A model with bilinear isotropic strengthening was used to simulate the behavior of steel reinforcement. The steel's mechanical characteristics were taken from compliance with the AIII reinforcement and shown in Table 2.

Table 2

Physical and mechanical properties of steel rebar

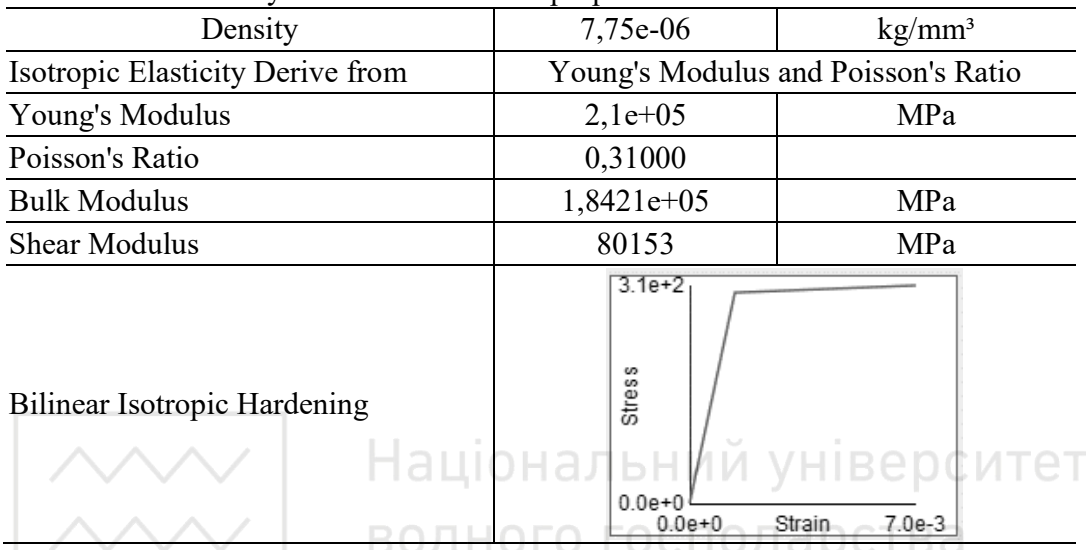

For composite reinforcement, a linear orthotropic behavior model is adopted, and its characteristics showed in Table 3.

Table 3

Physical and mechanical properties of composite rebar

\begin{tabular}{l|c|c}
\hline \multicolumn{1}{c|}{ Density } & $1,8 \mathrm{e}-06$ & $\mathrm{~kg} / \mathrm{mm}^{3}$ \\
\hline Orthotropic Elasticity & & \\
\hline Young's Modulus X direction & 71000 & $\mathrm{MPa}$ \\
\hline Young's Modulus Y direction & 71000 & $\mathrm{MPa}$ \\
\hline Young's Modulus Z direction & 71000 & $\mathrm{MPa}$ \\
\hline Poisson's Ratio XY & 0,20 & \\
\hline Poisson's Ratio YZ & 0,40 & \\
\hline Poisson's Ratio XZ & 0,20 & \\
\hline Shear Modulus XY & 9000,0 & $\mathrm{MPa}$ \\
\hline Shear Modulus YZ & 8214,3 & $\mathrm{MPa}$ \\
\hline Shear Modulus XZ & 9000,0 & $\mathrm{MPa}$ \\
\hline Compressive Ultimate Strength & 0 & $\mathrm{MPa}$ \\
\hline Compressive Yield Strength & 1200,0 & $\mathrm{MPa}$ \\
\hline Tensile Ultimate Strength & 1200,0 & $\mathrm{MPa}$ \\
\hline Tensile Yield Strength & 1200,0 & $\mathrm{MPa}$ \\
\hline
\end{tabular}




\section{Numerical model}

The original simulation was done on a steel rebar model (St). The diameter of the upper rods is $6 \mathrm{~mm}$, and the lower ones are $12 \mathrm{~mm}$. For models with composite rebar, three options for bar diameters accepted:

diameters of composite and steel rebars are equal (C_eqv_D);

the diameters of composite rebar were calculated based on conditions of equal bearing capacity with steel rebar (C_eqv_F);

The composite rebar's diameters are calculated from the conditions of equal strain with steel rebar (C_eqv_e).

The methods for calculating the corresponding diameters of composite rebar are discussed below.

For all four models, meshes with a cell size of $20 \mathrm{~mm}$ were created (Fig. 2).

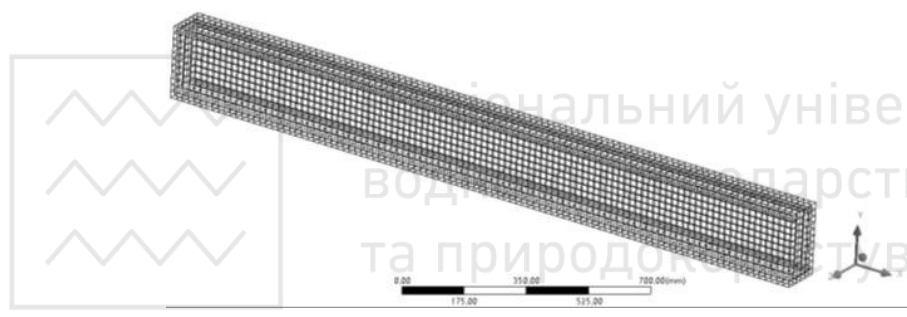

Fig. 2. Mesh of the numerical model of a reinforced beam

In all models, loading performs by applying a concentrated load to the upper chord of the beam. The load was applied in ten steps with a maximum value of $5000 \mathrm{~N}$ for each of the two concentrated loads (Fig. 3). The load values for each stage give in table 4. In addition to concentrated loads, gravity acts on the beam.

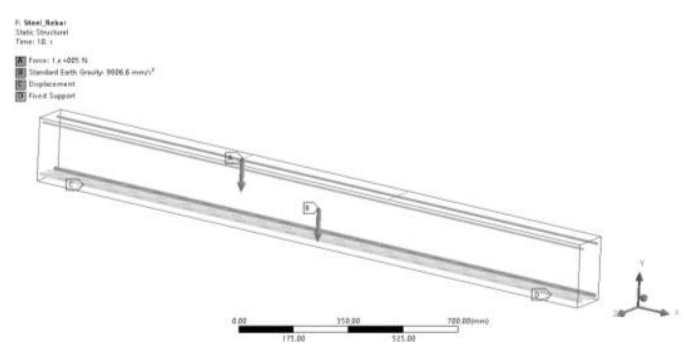

Fig. 3. Scheme of fixing the beam and distribution of loads 
Amount of load at each step of loading

\begin{tabular}{c|c|c|c|c}
\hline Steps & Time $[\mathrm{s}]$ & $\mathrm{X}[\mathrm{N}]$ & $\mathrm{Y}[\mathrm{N}]$ & $\mathrm{Z}[\mathrm{N}]$ \\
\hline 1 & 0 & 0 & 0 & 0 \\
\hline 1 & 1 & 0 & 0 & 0 \\
\hline 2 & 2 & 0 & -11111 & 0 \\
\hline 3 & 3 & 0 & -22222 & 0 \\
\hline 4 & 4 & 0 & -33334 & 0 \\
\hline 5 & 5 & 0 & -44444 & 0 \\
\hline 6 & 6 & 0 & -55556 & 0 \\
\hline 7 & 7 & 0 & -66666 & 0 \\
\hline 8 & 8 & 0 & -77778 & 0 \\
\hline 9 & 9 & 0 & -88888 & 0 \\
\hline 10 & 10 & 0 & -100000 & 0 \\
\hline \multicolumn{7}{|r|}{}
\end{tabular}

\section{Method for calculating the diameters of composite rebars}

As mentioned earlier, the work considers four numerical models of a concrete beam, differing in material and diameters of rebars: St, C_eqv_D, C_eqv_F, C_eqv_e. In the first two models (St and C_eqv_D), the diameters of the rebars are equal.

For the third model - C_eqv_F, the composite rebar diameter was selected based on the conditions for ensuring elastic deformation stages the same bearing capacity as steel rebar. The bearing capacity of the rebar $\mathrm{F}$ is

$$
F=\sigma \pi r^{2} .
$$

In equal bearing capacity rebar made of steel and basalt, the condition must be met

$$
\sigma_{k, s t} \pi r_{s t}^{2}=\sigma_{k, c p z} \pi r_{c p z}^{2}
$$

Hence

$$
r_{c p z, \sigma}=r_{s t} \sqrt{\frac{\sigma_{k, s t}}{\sigma_{k, c p z}}} .
$$

where $F$ - rebar load

$\sigma$ - rebar stress

$\sigma_{k, s t}-$ characteristic strength of steel rebar

$\sigma_{k, c p z}-$ characteristic strength of composite rebar

$r_{s t}-$ steel rebar radius

$r_{c p z}$ - composite rebar radius 
$r_{c p z, \sigma}-$ radius of composite rebar that provides the same bearing capacity as steel rebar.

For the considered model $\sigma_{k, s}=295 \mathrm{MPa}, \sigma_{k, c p z}=1200 \mathrm{MPa}$. Therefore, the radius of the lower belt rebar takes:

$$
6 \cdot \sqrt{\frac{295}{1200}}=2,97[\mathrm{~mm}]
$$

Similarly, the upper chord's composite rebar' radius was calculated, which is $1.48 \mathrm{~mm}$.

In the fourth model - C_eqv_e, the diameters of the composite rebar were calculated from the conditions for ensuring the same strain of the composite and steel bars at the stage of elastic deformations. The following was considered

$$
E=\frac{\Delta \sigma}{\Delta \varepsilon},
$$

where

$$
\varepsilon=\frac{\Delta l}{l} \text { and } \sigma=\frac{F}{A}
$$

For the round section

$$
A=\pi \cdot r^{2} .
$$

Thus, for a circular section

$$
\sigma=\frac{F}{\pi r^{2}}, \text { a } \Delta \sigma=\frac{F_{2}-F_{1}}{\pi r^{2}}=\frac{\Delta F}{\pi r^{2}} .
$$

Hence

$$
E=\frac{\Delta F \cdot l}{\Delta l \cdot \pi \cdot r^{2}} .
$$

Let us denote Young's modulus of steel rebar through $E_{s t}$, composite through $E_{c p z}$ and the cross-sectional radii of the steel rebar, respectively, through $r_{s t}$, and the composite $-r_{c p z}$. For the rods to have the same relative elongation $\Delta l_{c p z}=\Delta l_{s t}$ at the same $\Delta F$, the condition must be met

$$
\frac{\Delta F \cdot l}{E_{c p z} \cdot \pi \cdot r^{2}}=\frac{\Delta F \cdot l}{E_{s t} \cdot \pi \cdot r^{2}} .
$$

Removing the components with equal values from equality, we obtain 


$$
\frac{1}{E_{c p z} \cdot r_{c p z}^{2}}=\frac{1}{E_{s t} \cdot r_{s t}^{2}}
$$

Hence

$$
r_{c p z, \varepsilon}=r_{s t} \sqrt{\frac{E_{s t}}{E_{c p z}}},
$$

where $r_{c p, \varepsilon}$ - the composite rebar radius that provides the same strain as steel rebar.

For the considered model $E_{s}=2,1 \mathrm{e}+05 \mathrm{MPa}, E_{c p z}=7,1 \mathrm{e}+04 \mathrm{MPa}$. The radius of the bars of the lower chord

$$
6 \cdot \sqrt{\frac{2,1 e+05}{7,1 e+04}}=10,32[\mathrm{~mm}]
$$

Similarly, the radius of the composite rods of the upper chord is calculated as $5.16 \mathrm{~mm}$.

The diameters of the rebar of all numerical models are seen in table 5 .

\begin{tabular}{|c|c|c|c|c|}
\hline \multirow[b]{2}{*}{ Top/bottom beam chord } & \multicolumn{4}{|c|}{ Model code } \\
\hline & St & C_eqv_D & C_eqv_F & $\underset{\text { e }}{\mathrm{C} \_ \text {eqv }}$ \\
\hline $\begin{array}{l}\text { The diameter of rods of the upper belt } \\
{[\mathrm{mm}]}\end{array}$ & .0 & 6.0 & 2.96 & 10,3 \\
\hline $\begin{array}{l}\text { The diameter of rods of the bottom belt } \\
\text { [mm] }\end{array}$ & $2.0^{1}$ & 12.0 & 5.94 & 20.6 \\
\hline
\end{tabular}

Table 5

Diameters of bar reinforcement of beam models

\section{Research results}

Based on the simulation results for different models, the beam's deflections, relative deformations of concrete, axial compressive and tensile stresses in the concrete, axial stresses in the upper and lower chords' rods, and the degree of utilization of the rod material were compared.

The dependence of the beam deflections on the load is shown in Fig. 4. 


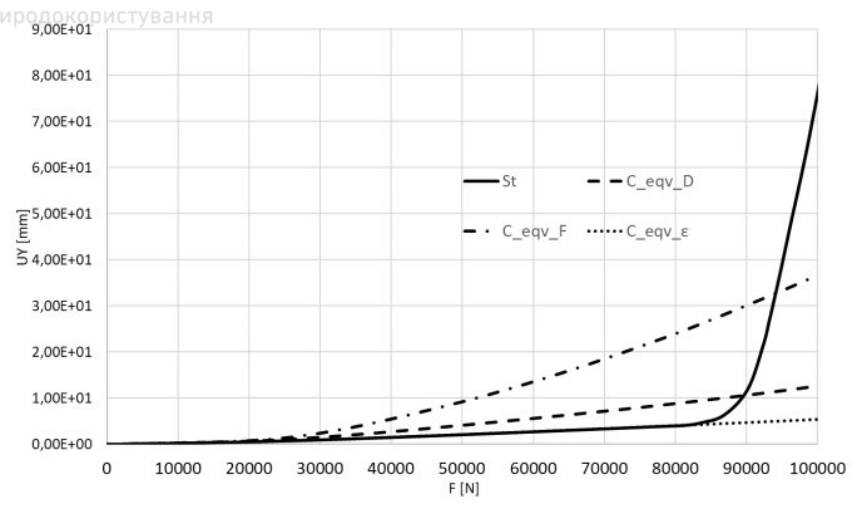

Fig. 4. Vertical deflections of reinforced concrete beams

It can be seen from the graph that the nonlinear deflection of the beam in the St model begins at a load of $85.6 \mathrm{kN}$. The most considerable deflections are observed in the C_eqv_F model. As expected, the smallest deflections are in the C_eqv_E model. Simultaneously, until the onset of plastic deformations in steel rebar, the deflections in the model $\mathrm{St}$ and $\mathrm{C}_{-}$eqv_ $\varepsilon$ are practically equal. With the onset of plastic deformations in steel rebar at a load of 85.6 $\mathrm{kN}$, the St model's deflections increase sharply, while in the C_eqv_E model, they only slightly increase.

The deflections in the C_eqv_F model significantly exceed the deflections in the St model at all loads. Nevertheless, with a load of 93.3 $\mathrm{kN}$, the deflections in the steel rebar plastic deformations zone in both models are equalized. Further increase in the load, the deflections in the C_eqv_F model are significantly lower than in the St.

As the load increases, the ratio of the deflection values in the steel rebars elastic work zone for models St and C_eqv_F changes from 1.15 to 4.69 , and models St and C_eqv_D from 1.11 to 2.02. The models' maximum strain was determined in the lower belt seat central part (Fig. 5).

The simulation results are shown in Fig. 6. The patterns of manifestation of relative deformations of all models are practically similar to the manifestation of deflections. However, the ratio of the relative deformations of different models is somewhat less. 

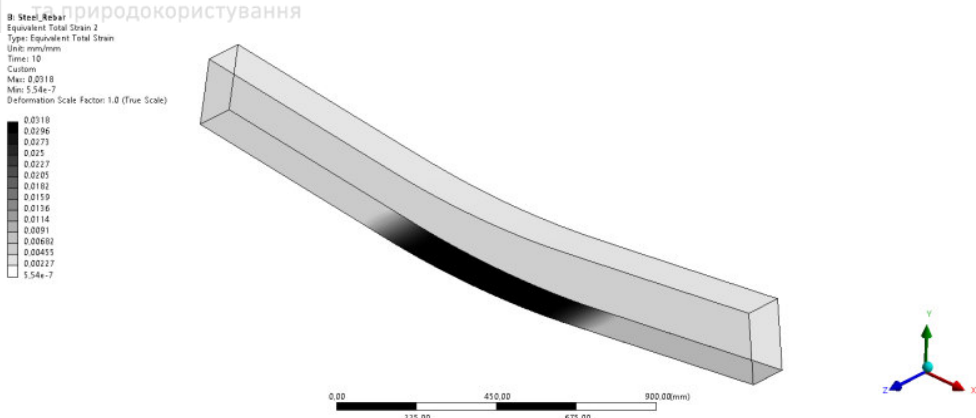

Fig. 5. Concrete strain in the lower chord of the model with steel rebar (St) at maximum load

The strain values ratio in the zone of steel reinforcement elastic work for models St and C_eqv_F varies from 1.00 to 4.28, and for models St and C_eqv_D from 1.00 to 1.62. The lowers values of the relative deformations' ratios compared with the deflections are explained by the fact that the deformations of the lower chord of the beam and the upper one take part in deflections.

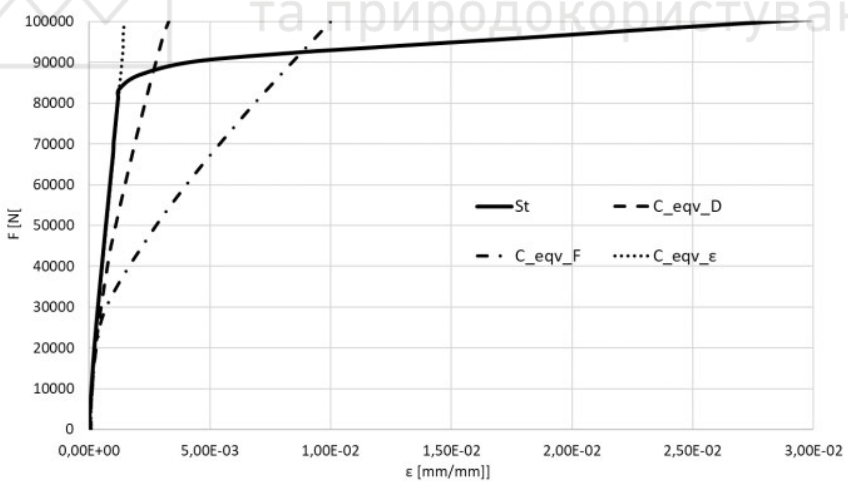

Fig. 6. Strains of numerical models of reinforced concrete beams

Per [17], the tensile strain of concrete, at which cracking begins, is determined by the formula

$$
\varepsilon_{b t R}=\frac{1}{15} \sqrt[3]{\left(\frac{R_{b t}}{E_{b n}}\right)^{2}}
$$


For the concrete used in the model, the limiting strain of concrete after which cracking occurs $\varepsilon_{b t}=1,48 \mathrm{E}-04[\mathrm{~mm} / \mathrm{mm}]$.

A detailed examination of the relative deformations in the load zone that corresponds to the moment of crack initiation (Fig. 7) shows that crack formation occurs earlier in all models with composite rebars. In the C_eqv_F model, cracking begins at a load of $18.5 \%$, in C_eqv_D by $13.1 \%$, C_eqv_ $\varepsilon-$ by $7.0 \%$ lower than in the St.

The distribution of strain in the beam models St and C_eqv_D showed in Figs 8 and 9. The relative deformations in the figure are determined at a load of $83.57 \mathrm{kN}$, at which plastic deformations of steel rebars begin in model $\mathrm{St}$.

The C_eqv_D model, in comparison with the St model, has significantly larger relative deformations both in value and in length along the lower chord of the beam.

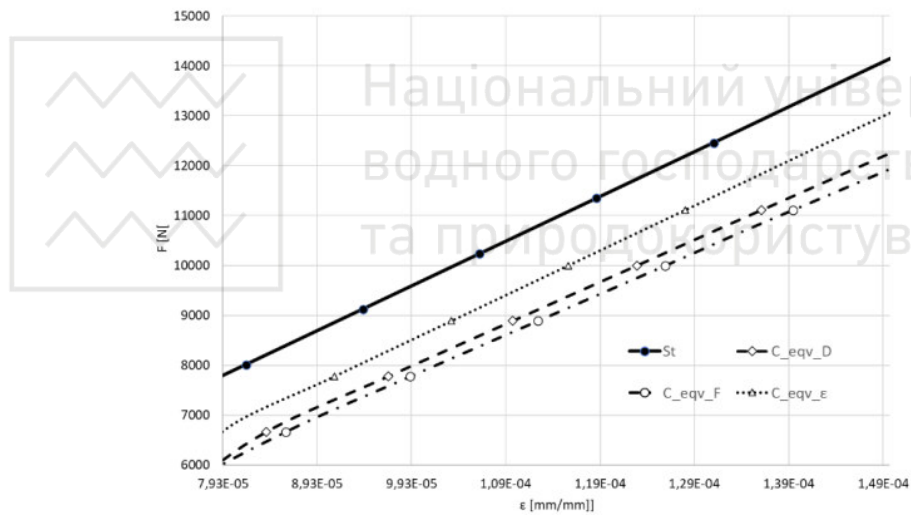

Fig. 7. Relative deformations of numerical models of reinforced concrete beams in the load zone that corresponds to the beginning of cracking
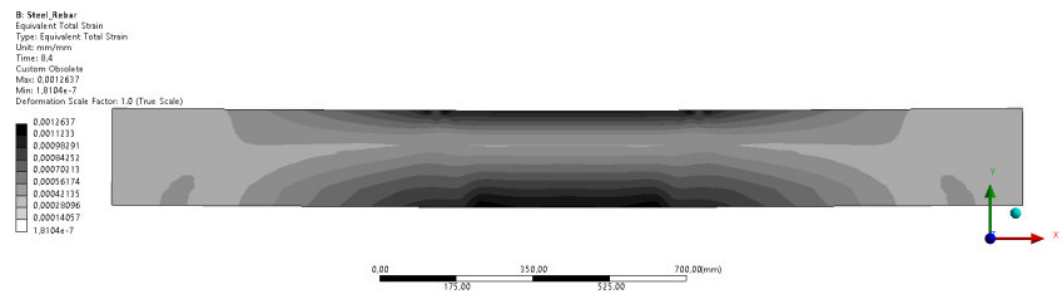

Fig. 8. Equivalent total strain in model St under a load that is corresponding to the onset of plastic deformations of steel reinforcement $(83.57 \mathrm{kN})$ 

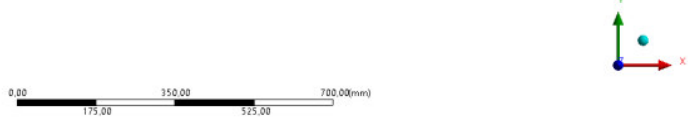

Fig. 9. Equivalent total strain in model C_eqv_D under a load that is corresponding to the onset of plastic deformations of steel reinforcement $(83.57 \mathrm{kN})$

Cracking limits all models' lower chords' maximum stresses to concrete's ultimate tensile strength (Figure 10). Therefore, after the onset of crack formation, the nature of stress growth in the lower belt for all models does not differ significantly.

The growth rate of stresses in the upper belt for different models has significant differences. With increasing load, compressive stresses increase the fastest in the model C_eqv_F. The higher rate of growth of compression stresses in the upper belt of the C_eqv_F and C_eqv_D models is associated with a decrease in the compressed zone's size (Fig. 11).

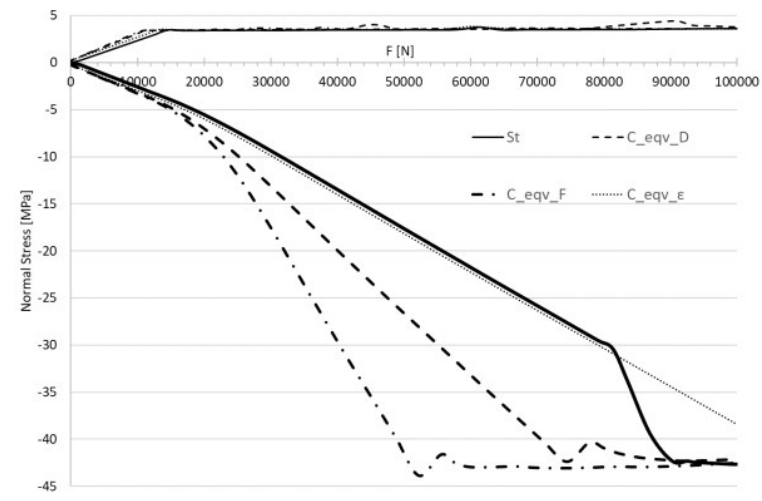

Fig. 10. Maximum stresses in the upper and lower chord of various beam models 


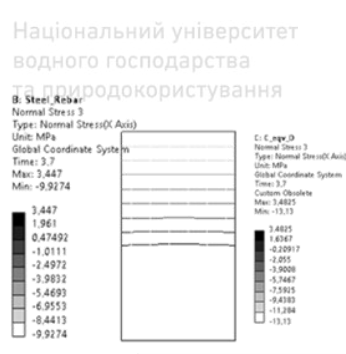

a)

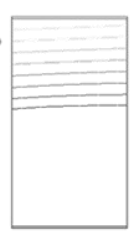

b)

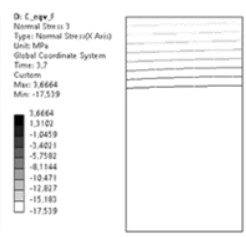

c)

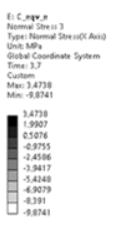

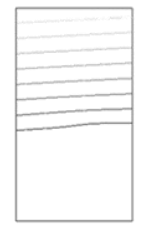

d)

Fig. 11. Distribution of normal stresses along with height in the central part of various beam models. $a-\mathrm{St} ; b-\mathrm{C}$-eqv_D; $c-\mathrm{C}$-eqv_F; $d-\mathrm{C} \_$eqv_e. Load $30 \mathrm{kN}$

In the model with steel rebar (St), a significant increase in stresses in the beam's upper chord occurs when plastic deformations appear in the lower chord rebar. The loss of the upper chord's bearing capacity in models St, C_eqv_D, and C_eqv_F occurs at tensile stresses of about $42 \mathrm{MPa}$. This value is higher than the ultimate strength of concrete under uniaxial compression $(38.5 \mathrm{MPa})$ but lower than the biaxial compressive strength $(59.78 \mathrm{MPa})$. The loss of concrete bearing capacity in the compressed zone in the C_eqv_F model occurs at a load of $52.2 \mathrm{kN}, \mathrm{C}$ eqv_D - a load of $74.4 \mathrm{kN}, \overline{\mathrm{St}}$ - $88.8 \mathrm{kN}$, C_eqv_e - at a load of more than $100 \mathrm{kN}$. If we assume that the loss of the bearing capacity of a beam with steel rebars occurs not when the ultimate strength of concrete in compression is reached but at the beginning of plastic deformations of the reinforcement, then the bearing capacity of the St model not will be $88.8 \mathrm{kN}$, but $81.2 \mathrm{kN}$.

Figures 12 and 13 show the nature of stress changes of the upper and lower chords rebars. The fastest increase in stresses in the reinforcement of the lower chord is observed in the C_eqv_F model. In models $\mathrm{St}$ and $\mathrm{C}$ _eqv_F, almost the same voltages occur with increasing load.

The stresses in the lower chord rebars of the C_eqv_e model at any loading level are significantly less than in the St and C_eqv_F models. The distribution of stresses in the reinforcement of the upper chord has other dependencies (Fig. 13). 


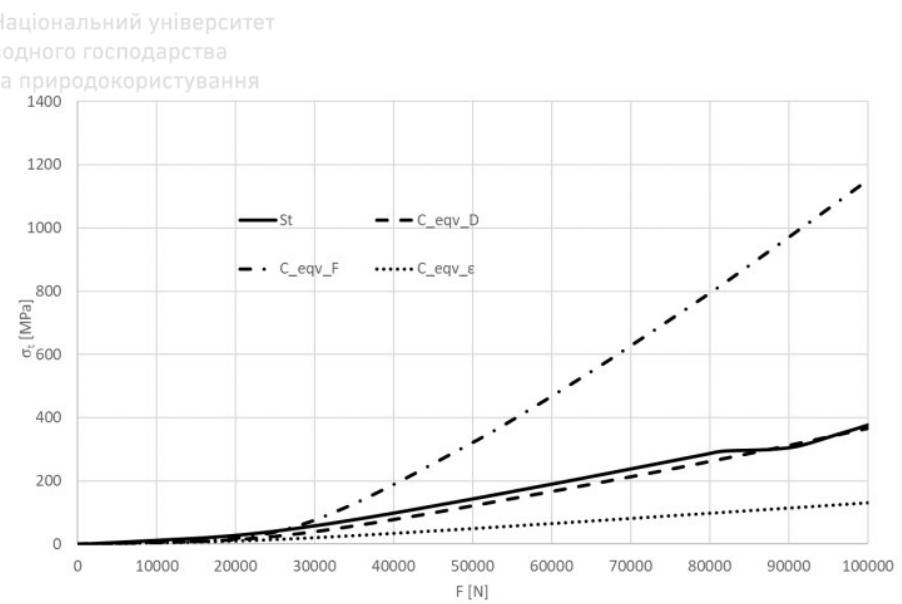

Fig. 12. Normal stresses in the lower chord rebar

The highest compressive stresses are observed in the St. The voltage is slightly lower in the C_eqv_F model, even lower in the C_eqv_D model. Model C_eqv_e has the lowest stresses in the top chord reinforcement.

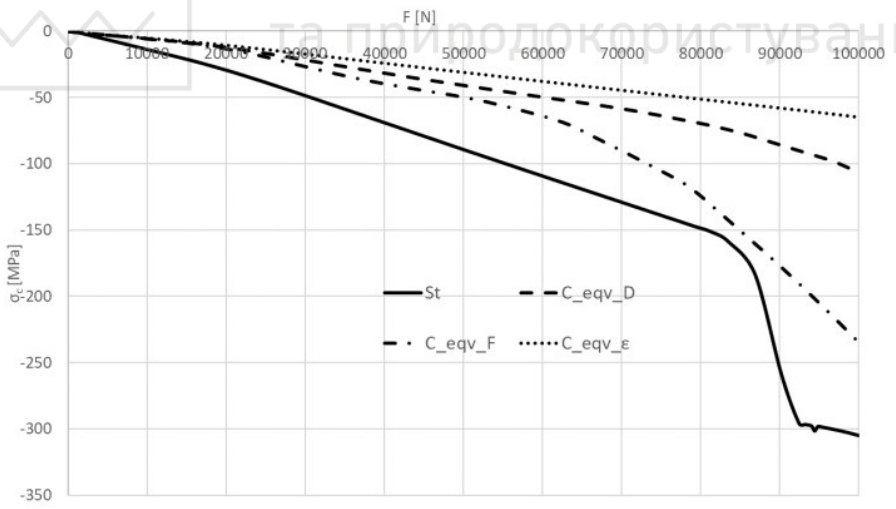

Fig. 13. Normal stresses in the upper chord rebar

Figures 14 and 15 show the coefficients of using the bearing capacity of the reinforce of the models.

The steel reinforcement bearing capacity's utilization factor was determined as the reinforcement's stress ratio to its yield point. For composite reinforcement, this is the ratio of stress to the ultimate 
strength of the reinforcement. At the same loads, the maximum utilization factor for steel reinforcement of the St model, the minimum for the C_eqv_e model. At a load of $80 \mathrm{kN}$, the utilization factors of the bearing capacity of the lower reinforcement are: $\mathrm{St}-$ 0,99; C_eqv_D - 0,22; C_eqv_F - 0,66; C_eqv_e - 0,08. For the upper reinforcement, these indicators are: $\overline{\mathrm{St}}-0.51$; C_eqv_D 0.058; C_eqv_F 0.10; C_eqv_e - 0.04. Thus, underutilization of the bearing capacity of the material is observed for all models of composite reinforcement.

In the production of reinforced concrete, the price of both the concrete itself and the reinforcement elements is essential. Since the concrete volume in the models under consideration does not change significantly, only steel and composite rebar will be considered when calculating the cost indicators.

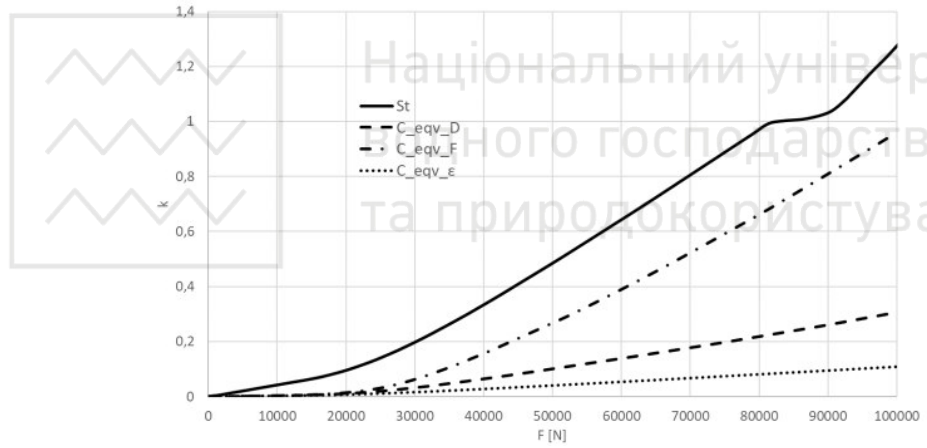

Fig. 14. Utilization factors of the bearing capacity of the bottom reinforcement

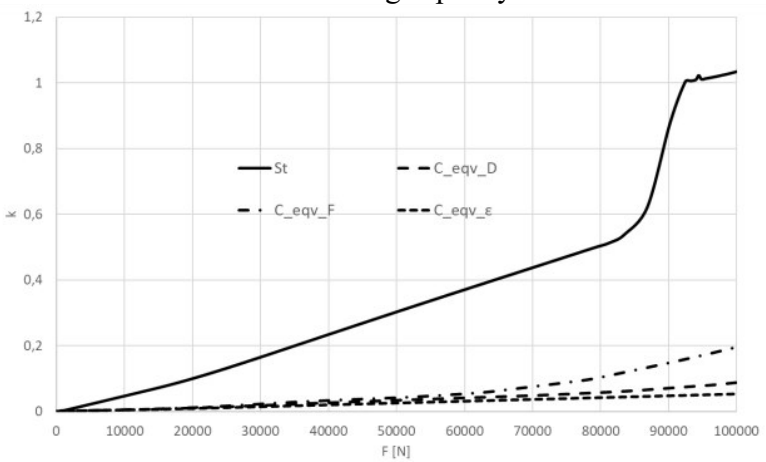

Fig. 15. Utilization factors of the bearing capacity of the upper reinforcement 
Prices are obtained from open sources: [18], [19] (as of $12 / 01 / 2021)$. Prices for one running meter of steel and composite reinforcement of various diameters showed in Table 6 . At the time of this writing, one hryvnia corresponded to USD 0.035 and EUR 0.029 .

Table 6

Price of one running meter steel and composite rebar

\begin{tabular}{c|c|c|c}
\hline Item No. & Diameter $[\mathrm{mm}]$ & Rebar type & Price [UAH] \\
\hline 1 & 6 & steel & 6,5 \\
\hline 2 & 12 & steel & 17 \\
\hline 3 & 3 & composite & 2,5 \\
\hline 4 & 6 & composite & 4,5 \\
\hline & 10 & composite & 13,7 \\
\hline 5 & 12 & composite & 18 \\
\hline 6 & 20 & composite & 52,7 \\
\hline
\end{tabular}

The models under consideration use three rods with a total length of $6.24 \mathrm{~m}$ in the lower chord and two rods with a total length of 4.16 $\mathrm{m}$ in the beam's upper chord. The calculation of the cost of reinforcement showed in table 7 .

Table 7

Calculation of the cost of reinforcing elements

\begin{tabular}{c|l|c|c|c|c}
\hline \multirow{2}{*}{$\begin{array}{c}\text { Top/bottom } \\
\text { beam chord }\end{array}$} & Parameter & St & C_eqv_D & C_eqv_F & $\begin{array}{c}\text { C_eqv_ } \\
\text { e }\end{array}$ \\
\cline { 3 - 6 } & Diameter [mm] & 6 & 6 & 3 & 10 \\
\hline \multirow{4}{*}{ Upper } & $\begin{array}{l}\text { Price of one running } \\
\text { meter [UAH] }\end{array}$ & 6,5 & 4,5 & 2,5 & 13,7 \\
\cline { 2 - 6 } & Amount & 4,16 & 4,16 & 4,16 & 4,16 \\
\cline { 2 - 6 } & Total [UAH] & 27,04 & 18,72 & 10,4 & 56,992 \\
\hline \multirow{5}{*}{ Lower } & Diameter [mm] & 12 & 12 & 6 & 20 \\
\cline { 2 - 6 } & $\begin{array}{l}\text { Price of one running } \\
\text { meter [UAH] }\end{array}$ & 17 & 18 & 4,5 & 52,7 \\
\cline { 2 - 6 } & Amount & 6,24 & 6,24 & 6,24 & 6,24 \\
\cline { 2 - 6 } & Total [UAH] & 106,08 & 112,32 & 28,08 & 328,848 \\
\hline \multicolumn{1}{|c|}{} & 133,12 & 131,04 & 38,48 & 385,84 \\
\hline & In total & 1 & 0,98 & 0,29 & 2,9 \\
\hline
\end{tabular}

The last line of the table shows the relationship between the cost of composite reinforcement of the corresponding models and the cost of steel reinforcement. Calculations show that the C_eqv_F model has the lowest cost of reinforcement, with the bearing capacity of the composite reinforcement being equal to the bearing capacity of the 
steel reinforcement. The cost of the reinforcement model C_eqv_D differs slightly from the cost of steel reinforcement, and the cost of the reinforcement model C_eqv_e is almost three times the cost of steel reinforcement.

\section{Conclusions}

The results obtained in work allow making a comparative analysis of various models of using composite reinforcement. All parameters of the composite model are compared with the corresponding parameters of the steel rebar model. The analysis results are summarized in Table 8 .

Table 8

Summary indicators of models with steel and composite reinforcement

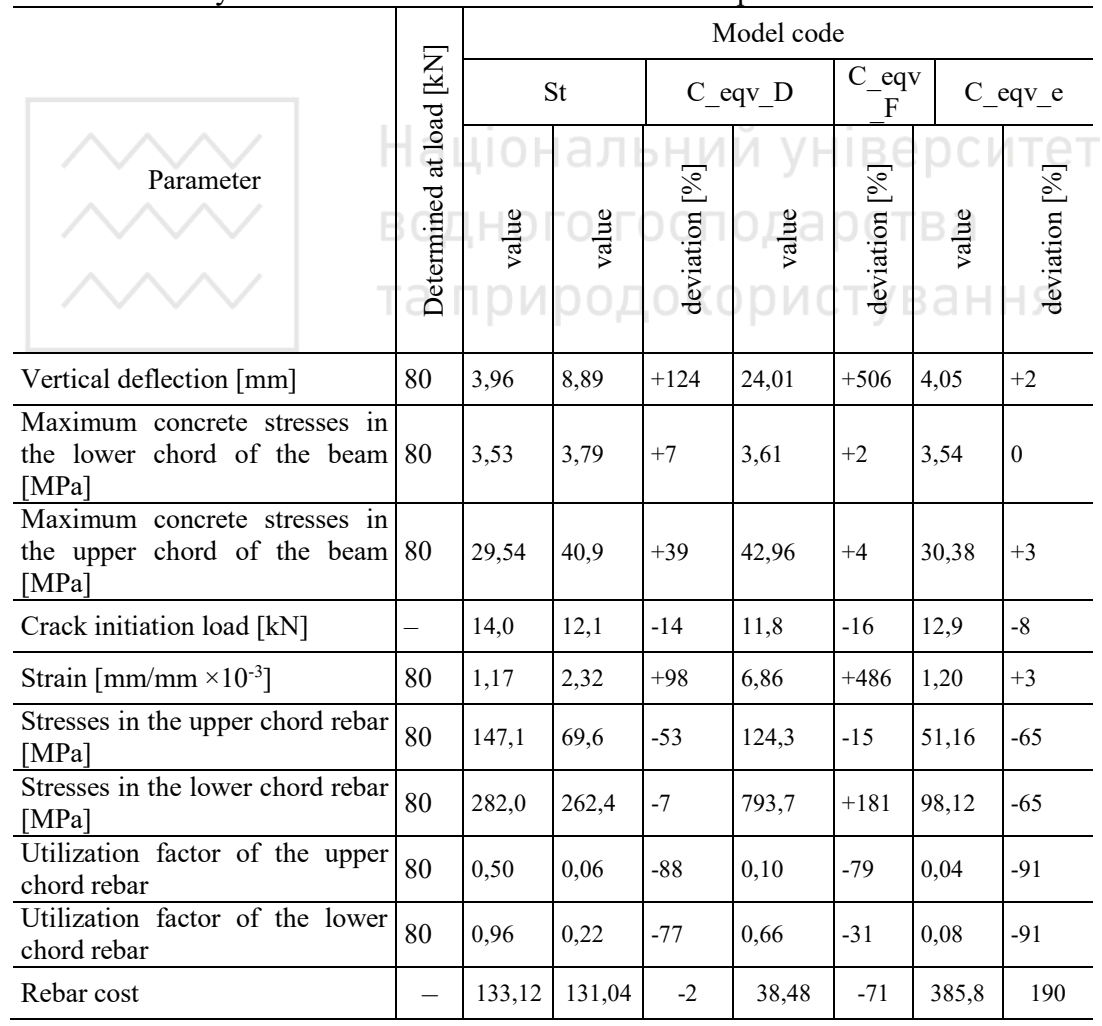


The C_eqv_e model provides the best beam performance. In this case, deformations are provided at the level of deformations of the beam with steel reinforcement, and the stresses in concrete practically do not differ from the corresponding stresses in the model St. The calculation obtained lower loads at which cracks begin to form. However, the utilization factor of the bearing capacity of the reinforcement in this model is shallow. The cost of reinforcing elements is almost three times the cost of steel rods. The model also showed lower loading values at which cracks start to form.

The C_eqv_F model can significantly reduce the cost of purchasing reinforcement. The advantage of a model with reinforcement of the same bearing capacity with steel reinforcement on this ended. The deformation of the model is 5-6 times greater than in control. The upper and lower chords' concrete stresses are higher than in a beam with steel rebar. Cracking begins at loads $16 \%$ lower, and the loss of the beam's bearing capacity occurs at $35 \%$ lower loads (Fig. 10) than in the model St.

Model C_eqv_F has reinforcement diameters equal to corresponding diameters of steel reinforcement of control model St. This model, in comparison with the control (St), has only disadvantages. At the same loads, the deformation in it is more significant, the stresses in the concrete are higher, cracking and loss of bearing capacity begins earlier than in a beam with steel reinforcement. The utilization factors of the bearing capacity of the reinforcement are also insignificant.

The analysis carried out in this work at this stage of research did not reveal the significant advantages of composite rod reinforcement compared to steel. Benefits can be obtained with a significant reduction in the cost of composite reinforcement.

The high creep values of amorphous vitreous substances can significantly affect the deformation and bearing capacity of structures over long periods. Therefore, further research should be aimed at studying the creep parameters of composite reinforcement.

\section{Bibliography}

1. Masuelli, M. (2013). Fiber Reinforced Polymers - The Technology Applied for Concrete Repair. Rijeka, Croatia: InTech.

2. Lapko, A, Urbański, M. (2015). Experimental and theoretical analysis of deflections of concrete beams reinforced with basalt rebar. Arch Civ Mech Eng,15, 223-30. 
3. Kim, H.S, Shin, Y.S. (2011). Flexural behavior of reinforced concrete (RC) beams retrofitted with hybrid fiber-reinforced polymers (FRPs) under sustaining loads. Compos Struct, 93, 802-11.

4. Luccioni, B., Rougier, V.C. (2013) Numerical analysis of fibre reinforced polymer retrofitted masonry panels. Engineering Structures, 49, 360-72.

5. Campbell, F.C. (2010) Structural Composite Materials. ASM International.

6. Pico, D., Steinmann, W. (2016) Synthetic fibers for composite applications. Fibrous and Textile Materials for Composite Applications, Singapore: Springer, 135-170.

7. Holmes, M. (2014) Global carbon fibre market remains on upward trend. Reinf Plast, 58, 38-45.

8. Wang, X., Shi, J., Liu, J., Yang, L., Wu, Z. (2014) Creep behavior of basalt fiber reinforced polymer tendons for prestressing application. Mater Des, 59, 558-64.

9. Elgabbas, F., Vincent, P., Ahmed, E.A., Benmokrane, B. (2016) Experimental testing of basalt-fiber-reinforced polymer bars in concrete beams. Compos Part B-Eng, 91, 205-18.

10. Fiore, V., Scalici, T., Di Bella, G., Valenza, A. (2015) A review on basalt fibre and its composites. Compos Part B-Eng, 74, 74-94.

11. Ramakrishnanm V., Panchalan, R. (2005) A new construction material - noncorrosive basalt bar reinforced concrete. ACI, 229, 253-270

12. Thorhallsson, E.R., Snaebjornsson, J.T. (2016) Basalt Fibers as New Material for Reinforcement and Confinement of Concrete. Solid State Phenomena, 249. DOI:10.4028/www.scientific.net/SSP.249.79

13. Gunnarsson, A., Thorhallsson, E.R., Snæbjornsson, J.T. (2014) Simulation of experimental research of concrete beams prestressed with BFRP tendons. In proceedings of the XXII Nordic Concrete Research Symposium Reykjavik, Vodskov, 153-156.

14. Thorhallsson, E.R., Gudmundsson, S.H. (2013) Test of prestressed basalt FRP concrete beams with and without external stirrups. In: Dancygier AV, editor. Proceedings of Fib symposium Engineering a Concrete future: Technology, modelling \& Construction, Tel Aviv, 393-396

15. Sakhno, S., Liulchenko, Y., Chyrva, T., Yanova, L., Pischikova O. (2020) Determination of bearing capacity and calculation of the gain of the damaged span of a railway overpass by the finite element method. Topical scientific researches into resource-saving technologies of mineral mining and processing. - Sofia Publishing house "St.Ivan Rilski", 326-339

16. Sakhno, S., Liulchenko, Y., Bilashenko K. (2020) Investigation of the applicability of nonlinear numerical models of concrete strength for modeling the destruction of concrete prisms Hirnychyy visnyk, 107 68-73

17. Nikulin, A.I. (2014) To determining the limiting relative deformation of concrete in the extended area of a bended reinforced concrete element. Sovremennyye problemy nauki i obrazovaniya, 6. Retrieved from http://www.science-education.ru/ru/article/view?id=16844

18. Price list "Price for metal rolling". Retrieved from https://riber.com.ua/g397304-armatura-stalnaya (as of 12/01/2021)

19. Price list "Price for Composite Reinforcement". https://dp.dnproekt.com/kompozitnaya-armatura-na-sklade-kupitstekloplastikovuyu-armaturu-v-krivom-roge (as of 12/01/2021) 